\title{
Proteomic profile-based screening of potential protein biomarkers in the urine of patients with nephrotic syndrome
}

\author{
YU WANG, CHUNXIA ZHENG, XIA WANG, KE ZUO and ZHIHONG LIU \\ National Clinical Research Center of Kidney Diseases, Jinling Hospital, Nanjing University School of Medicine, \\ Nanjing, Jiangsu 210002, P.R. China
}

Received July 27, 2016; Accepted May 23, 2017

DOI: $10.3892 / \mathrm{mmr} .2017 .7329$

\begin{abstract}
Nephrotic syndrome is not a single disease; rather, it is a term for numerous diseases and pathological types. Renal biopsy is of use in determining the diagnosis and prognosis, and for guiding treatment; however, the use of this intervention is limited due to its invasive nature. Abnormal kidney-derived proteins in the urine of patients provide useful information regarding numerous pathological processes that occur in the kidneys, and may be considered a potential non-invasive biomarker for kidney disease. Proteomic analysis exhibits the advantage of being high-throughput and has previously been used to identify biomarkers of disease. The present study aimed to identify abnormal kidney-derived proteins in the urine of patients with nephrotic syndrome using a novel proteomic strategy. Urine samples from 5 patients with nephrotic syndrome were subjected to acetone precipitation and albumin/immunoglobulin $\mathrm{G}$ depletion prior to analysis by two-dimensional liquid chromatography tandem mass spectrometry. The resulting data were compared to a publicly available proteomic database of normal human plasma/urine and normal human kidney in PeptideAtlas, and of normal human kidney in the Human Protein Atlas. Candidate biomarkers were validated using ELISA analysis in 60 patients with nephrotic syndrome: 30 with focal segmental glomerulosclerosis (FSGS) and 30 with minimal change disease (MCD), as well as in 30 healthy controls. The initial screening identified 809 proteins in the urine of patients with nephrotic syndrome. A total of $13 / 809$ proteins were additionally present in the kidney proteome of PeptideAtlas and the Human Protein Atlas, although not in normal human urine and normal human plasma according to PeptideAtlas; these were referred to as 'kidney-derived disease-associated proteins'. One of the
\end{abstract}

Correspondence to: Dr Zhihong Liu, National Clinical Research Center of Kidney Diseases, Jinling Hospital, Nanjing University School of Medicine, 305 East Zhongshan Road, Nanjing, Jiangsu 210002, P.R. China

E-mail: liuzhihong@nju.edu.cn

Key words: urine, biomarker, proteomic analysis, nephrotic syndrome, ubiquitin-60S ribosomal protein L40 kidney-derived disease-associated proteins, ubiquitin-60S ribosomal protein L40 (UBA52) was observed to be increased in the urine of patients compared with normal controls [Creatinine, $637 \mathrm{ng} / \mathrm{mg}(216-1,851)$ vs. $1.89 \mathrm{ng} / \mathrm{mg}$ (1.37-3.33), $\mathrm{P}<0.001$; and $18.58 \mathrm{ng} / \mathrm{mg}$ (11.11-46.25) vs. $1.89 \mathrm{ng} / \mathrm{mg}$ (1.37-3.33), $\mathrm{P}<0.001)]$, and the urinary UBA52 levels were significantly increased in patients with FSGS compared with in patients with MCD $(\mathrm{P}<0.001)$. In conclusion, the present study identified potential novel urinary protein biomarkers for nephrotic syndrome, in addition to an extensive urinary proteomic profile of patients with nephrotic syndrome.

\section{Introduction}

Nephrotic syndrome is characterized by extensive proteinuria and hypoalbuminemia. It is not a single disease; rather, it is a term for numerous diseases and pathological types. Renal biopsy is of use in determining the diagnosis and prognosis, and for guiding treatment; however, its use is limited due to its invasive nature.

Proteomic analysis exhibits the advantage of being highthroughput, and it has been used to identify nephrotic syndrome biomarkers. However, the presence of abundant plasma proteins in the urine of patients with nephrotic syndrome makes proteomic identification of novel biomarkers difficult (1). Various attempts have been made towards improving biomarker identification, including two-dimensional electrophoresis mass spectrometry, surface enhanced laser-desorption ionization mass spectrometry and capillary electrophoresis combined with mass spectrometry (2-7). However, only a few highly abundant proteins, including albumin and $\alpha 2$-antitrypsin, have been identified. A comprehensive profile of the urine proteome of patients with nephrotic syndrome, with practical biomarkers, which reflects pathological type, prognosis and the underlying pathological process in nephrotic syndrome, remains lacking.

Antibody columns may be used to deplete high-abundance plasma proteins from urine samples to allow for the detection of lower abundance proteins (8-14). Two-dimensional liquid chromatography (2D-LC) separation decreases sample complexity by using two columns prior to tandem mass spectrometry (MS/MS) and exhibits increased power in detecting low-abundance proteins $(15,16)$. A method that combines antibody depletion with 2D-LC-MS/MS may facilitate the 
identification of biomarkers (17), although such a method has not previously been used to analyze nephrotic syndrome urine samples.

The 'black box' theory considers the kidney to be a black box with unique input and output proteomes (18). The plasma proteome represents the input proteome, and the urinary proteome represents the output proteome. According to this theory, proteins present in the urine may be derived from the plasma or kidney. Abnormal kidney-derived proteins in patient urine may provide information about numerous pathological processes occurring in the kidneys, and may be considered potential non-invasive biomarkers for kidney disease.

Due to the progression of proteomic technology and the development of bioinformatics, proteomic databases, including PeptideAtlas and the Human Protein Atlas, have been constructed for various tissues and body fluids; these databases provide the possibility of comparative studies to search kidney-derived proteins in the urine. As an important component of the Human Proteome Project, PeptideAtlas collects and processes published MS/MS-based proteomic data and classifies them into three proteomic databases: Normal human plasma, normal human urine and normal human kidney (19). The Human Protein Atlas is an antibody-based proteome database, which is focused on systemic examination of the human proteome by profiling cells and tissues using immunohistochemistry (20). Compared with PeptideAtlas, the Human Protein Atlas is less comprehensive, but more accurate.

In the present study, albumin/immunoglobulin (Ig) $\mathrm{G}$ antibody depletion was used in combination with 2D-LC-MS/MS to analyze urine samples from patients with nephrotic syndrome. The resulting data were compared to proteomic data from normal human plasma, normal human urine and normal human kidney in PeptideAtlas, and from normal human kidney in the Human Protein Atlas to identify potential biomarkers $(19,20)$.

\section{Patients and methods}

Patients. The present study was approved by the Ethics Committee of Jinling Hospital (Nanjing, China), and informed consent was obtained from all patients. A total of 5 patients with nephrotic syndrome (proteinuria $>3.5 \mathrm{~g} / 24 \mathrm{~h}$ and serum albumin $<30 \mathrm{~g} / \mathrm{l}$ ) were included in the initial phase (Table I). A total of 30 biopsy-confirmed patients with primary focal segmental glomerulosclerosis (FSGS), 30 biopsy-confirmed patients with minimal change disease (MCD), and 30 healthy controls were included in the validation phase (Table II).

Sample preparation. Fresh urine was collected in the morning under sterile conditions and stored at $4^{\circ} \mathrm{C}$, prior to centrifugation at 5,000 $\mathrm{x}$ for $30 \mathrm{~min}$ at $4^{\circ} \mathrm{C}$ on the same day. The supernatant was precipitated with $3 \mathrm{X}(\mathrm{v} / \mathrm{v})$ cold acetone for $2.5 \mathrm{~h}$ at $4^{\circ} \mathrm{C}$, followed by centrifugation at $14,000 \mathrm{x}$ g for $35 \mathrm{~min}$ at $4^{\circ} \mathrm{C}$. The precipitate was resuspended in $25 \mathrm{mM} \mathrm{NH}_{4} \mathrm{HCO}_{3}$ and subjected to protein quantitation using the Bradford method. The protein samples from 5 patients were mixed together, and the pooled sample was subsequently processed using a ProteoPrep Immunoaffinity Albumin and IgG Depletion kit (cat no. PROTIA; Sigma-Aldrich; Merck KGaA, Darmstadt, Germany) (21). A low-abundance fraction was collected, and protein quantitation was performed using the Bradford method.
Table I. Clinical and laboratory characteristics of the patients with nephrotic syndrome in the initial phase.

Patient ID

\begin{tabular}{lccccc}
\cline { 2 - 6 } Characteristic & 1 & 2 & 3 & 4 & 5 \\
\hline Age, years & 23 & 27 & 19 & 21 & 17 \\
Sex & $\mathrm{M}$ & $\mathrm{F}$ & $\mathrm{M}$ & $\mathrm{M}$ & $\mathrm{M}$ \\
24-h urine protein, & 6.75 & 8.68 & 8.99 & 6.25 & 6.68 \\
g/24 h & & & & & \\
$\begin{array}{l}\text { Serum albumin, g/l } \\
\text { Serum cholesterol, } \\
\text { mmol/l }\end{array}$ & 17.1 & 24.2 & 18.6 & 20.2 & 28.6 \\
$\begin{array}{l}\text { Serum creatinine, } \\
\text { mg/dl }\end{array}$ & 1.03 & 0.6 & 5.19 & 1.52 & 1.23 \\
\hline
\end{tabular}

M, male; F, female.

Protein digestion. Protein digestion was performed as described previously (22). Briefly, the sample was reduced with $20 \mathrm{mM}$ dithiothreitol at $37^{\circ} \mathrm{C}$ for $1 \mathrm{~h}$, and alkylated with $50 \mathrm{mM}$ iodoacetamide at room temperature in the dark for $45 \mathrm{~min}$. The sample was subsequently loaded into a $10 \mathrm{kDa}$ filtration unit (Pall Life Sciences, Port Washington, NY, USA) prior to the addition of $200 \mu \mathrm{l}$ UA buffer ( $8 \mathrm{M}$ urea in $0.1 \mathrm{M}$ Tris-HCl; $\mathrm{pH} 8.5)$. The UA wash was repeated once following centrifugation at $14,000 \mathrm{x}$ for $45 \mathrm{~min}$ at $4^{\circ} \mathrm{C}$. A volume of $200 \mu 150 \mathrm{mM} \mathrm{NH}_{4} \mathrm{HCO}_{3}$ was added, and the sample was centrifuged at $14,000 \mathrm{x} \mathrm{g}$ for $45 \mathrm{~min}$ at $4^{\circ} \mathrm{C}$. The wash was repeated once with $\mathrm{NH}_{4} \mathrm{HCO}_{3}$. Trypsin (Promega Corporation, Madison, WI, USA) was added at a final concentration of 1:20 for protein digestion at $37^{\circ} \mathrm{C}$ overnight. The peptides were collected by centrifugation of the filtration unit at $14,000 \mathrm{xg}$ for $40 \mathrm{~min}$ at $4^{\circ} \mathrm{C}$, and were subsequently desalted, dried and stored for future use.

Off-line $L C$. The digested peptides were fractionated using a high-pH reversed phase column (Waters Corporation, Milford, MA, USA; 4.6x250 mm; C18; $3 \mu \mathrm{m})$. For each fraction the injection volume was $8 \mu \mathrm{l}$. The samples were loaded onto the column in buffer A (1\%o aqueous ammonia and $99.9 \%$ water, $\mathrm{pH} 10)$, and eluted by buffer B1 (1\%o aqueous ammonia in $10 \%$ water and $90 \%$ acetonitrile; $\mathrm{pH} 10$; flow rate, $1 \mathrm{ml} / \mathrm{min}$ ). The gradient of buffer B1 was increased from 5 to $90 \%$ for $60 \mathrm{~min}$. The eluted peptides were collected at a rate of 1 fraction per minute. Following drying of each fraction, the fractions were combined at an interval of 2 components into 20 copies. LC-MS/MS was subsequently performed.

LC-MS/MS analysis. Samples were analyzed by LC-MS/MS using a reversed-phase $\mathrm{C} 18$ self-packing capillary LC column (100x0.075 mm; $3 \mu \mathrm{m}$; Bruker Corporation, Billerica, MA, USA) and SCIEX Triple-TOF5600 mass spectrometer (SCIEX, Framingham, MA, US). For reverse phase separation, the samples were loaded onto the column in buffer A (1\%o aqueous ammonia and $99.9 \%$ water, $\mathrm{pH} 10)$, the elution solution was $5-30 \%$ buffer B2 (0.1\% formic acid and $99 \%$ acetonitrile; flow 
Table II. Clinical and laboratory characteristics of patients with FSGS and MCD, and healthy controls in the validation stage.

\begin{tabular}{lcccc}
\hline Characteristic & $\begin{array}{c}\text { FSGS } \\
(\mathrm{n}=30)\end{array}$ & $\begin{array}{c}\text { MCD } \\
(\mathrm{n}=30)\end{array}$ & $\begin{array}{c}\text { Healthy controls } \\
(\mathrm{n}=30)\end{array}$ & P-value \\
\hline Age, years & $30 \pm 15$ & $22 \pm 7$ & $26 \pm 8$ & 0.01 \\
Sex, M/F & $20 / 10$ & $19 / 11$ & $18 / 12$ & 0.79 \\
24-h urine protein, g/24 h & $8.34 \pm 3.75$ & $7.09 \pm 2.80$ & - & 0.15 \\
Serum albumin, g/l & $23.8 \pm 4.0$ & $22.1 \pm 3.38$ & - & 0.08 \\
Serum cholesterol, $\mathrm{mmol} / \mathrm{l}$ & $11.6 \pm 3.8$ & $10.8 \pm 2.8$ & - & 0.34 \\
Serum creatinine, $\mathrm{mg} / \mathrm{dl}$ & $1.07 \pm 0.41$ & $0.78 \pm 0.19$ & - & 0.001 \\
\hline
\end{tabular}

FSGS, focal segmental glomerulosclerosis; MCD, minimal change disease; M, male; F, female.

speed, $300 \mathrm{nl} / \mathrm{min}$ ) and the elution time was $2 \mathrm{~h}$. For MS/MS analysis the following conditions were used: Ion spray voltage, $220 \mathrm{~V}$; curtain gas, 25 psi; nebulizer gas, 5 psi; auxiliary gas, 0 psi; temperature, $150^{\circ} \mathrm{C}$; declustering potential, $100 \mathrm{~V}$; mass range, 350-1,250 amu for MS and 100-1,800 amu for MS/MS; collision energy, $35 \mathrm{~V}$; and resolution (full width at half-maximum), 40,000 for MS and 20,000 for MS/MS. Analysis was conducted using the data-dependent approach. Following each full scan, 30 tandem scans were performed. The width of the mass-to-charge ratio peak of the parent ion was 0.7 amu with $35 \%$ of the standard collision energy. The dynamic exclusion time was $15 \mathrm{sec}$.

Bioinformatic analyses. The MS/MS spectra were retrieved using Mascot software (version 2.3.02; Matrix Science, Ltd., London, UK) and searched against the human subset of the UniProt database (www.uniprot.org). The following parameters were used: Enzyme, trypsin; no. error cutting sites, 2; error range of peptides and daughter ion mass, $0.05 \mathrm{Da}$; and carbamidomethylation was set as the fixed modification. All MS detection results used the reverse database retrieval method to evaluate the false positive rate of the data [false positive rate $=$ (number of peptide fragments identified by reverse database/number of peptide fragments identified by positive database) x100]. The retrieved results were analyzed using Scaffold software (version 4.0.1; Proteome Software Inc., Portland, OR, USA). The false positive rate of proteins and polypeptides was $<1 \%$. Each protein exhibited $\geq 2$ unique peptides.

Databases. The urine proteomic profile data from patients with nephrotic syndrome were compared to proteomic data from normal human plasma, normal human urine and normal human kidney using PeptideAtlas (http://www.peptideatlas. org/), and from normal human kidney using the Human Protein Atlas (http://www.proteinatlas.org/).

ELISA. The first-voided urine samples of patients were obtained on the morning of renal biopsy. A volume of $50 \mathrm{ml}$ urine was collected directly from the patients into sterile plastic tubes and was centrifuged at $3,000 \mathrm{xg}$ for $10 \mathrm{~min}$ at $4^{\circ} \mathrm{C}$ to remove cell debris and particulate matter. The samples were stored at $-80^{\circ} \mathrm{C}$ for subsequent analysis and were brought to room temperature prior to use. Repeated freeze-thaw cycles were avoided. ELISA was performed according to the manufacturer's protocol, using a Ubiquitin-60S ribosomal protein L40 (UBA52) Human ELISA kit (cat. no. DL-UBA52-Hu; Gentaur Europe BVBA, Kampenhout, Belgium). Samples were assayed in duplicate. The urinary UBA52 level was normalized to the urinary creatinine level to correct for differences in dilution. The final concentration of urinary UBA52 was calculated as the ratio of the urinary UBA52 level to the creatinine level (ng/mg creatinine).

Statistical analysis. GraphPad Prism software (version 5.0; GraphPad Software, Inc., La Jolla, CA, USA) was used for statistical analyses and graphical representations of the data in the validation stage. Descriptive statistical analysis was performed to assess all of the studied variables. Data that followed a normal distribution were analyzed using the Kolmogorov-Smirnov test. Data are expressed as the mean \pm standard deviation, or medians and interquartile ranges (25th and 75th percentiles), or as the number of patients for categorical variables. Differences among the means with normal distribution were compared using Student's t-test, and differences with non-normal distributions were compared using Fisher's exact test or the $\chi^{2}$ test for categorical variables, as presented in Table II. Quantitative data exhibiting non-normal distributions were analyzed by Kruskal-Wallis test, followed by Dunn's multiple comparisons test. Two-tailed $\mathrm{P}<0.05$ was considered to indicate a statistically significant difference.

\section{Results}

Protein identification. Proteomic analysis identified 809 proteins ( $\geq 2$ unique peptides). The top 14 most abundant proteins as revealed by spectral counting are presented in Table III. These 14 proteins accounted for $47.6 \%$ of the total protein spectra (Fig. 1).

Comparison of the urine proteome of patients with nephrotic syndrome and the normal human urine proteome. The data collected from nephrotic syndrome urine samples were compared with the normal human urine data in PeptideAtlas (19). In order to ensure comparability, only compared proteins exhibiting hits against $\geq 2$ unique peptides in the normal human urine proteome were analyzed $(n=1,940$ in normal urine proteome). The results of the present study 
Table III. Top 14 abundant proteins in the urine proteome of patients with nephrotic syndrome.

\begin{tabular}{rllcrr}
\hline Rank & UniProt & \multicolumn{1}{c}{ Description } & $\begin{array}{c}\text { Spectral } \\
\text { counting }\end{array}$ & $\begin{array}{r}\text { Molecular } \\
\text { weight, kDa }\end{array}$ & $\begin{array}{r}\text { Unique } \\
\text { peptides }\end{array}$ \\
\hline 1 & P02787 & Serotransferrin & 3,923 & 77 & 117 \\
2 & P02763 & Alpha-1-acid glycoprotein 1 & 3,882 & 24 & 40 \\
3 & P19652 & Alpha-1-acid glycoprotein 2 & 1,893 & 24 & 16 \\
4 & P00450 & Ceruloplasmin & 1,744 & 122 & 94 \\
5 & P25311 & Zinc-alpha-2-glycoprotein & 1,661 & 34 & 53 \\
6 & P01009 & Alpha-1-antitrypsin & 1,623 & 47 & 53 \\
7 & P00738 & Haptoglobin & 1,121 & 45 & 31 \\
8 & P04217 & Alpha-1B-glycoprotein & 977 & 54 & 102 \\
9 & P02768 & Albumin & 908 & 69 & 30 \\
10 & P02760 & Protein AMBP & 821 & 39 & 13 \\
11 & P01834 & Ig kappa chain C region & 766 & 12 & 20 \\
12 & P02766 & Transthyretin & 611 & 16 & 61 \\
13 & P01008 & Antithrombin-III & 610 & 53 & 11 \\
14 & P0CG05 & Ig lambda-2 chain C regions & 495 & & 15 \\
\hline
\end{tabular}

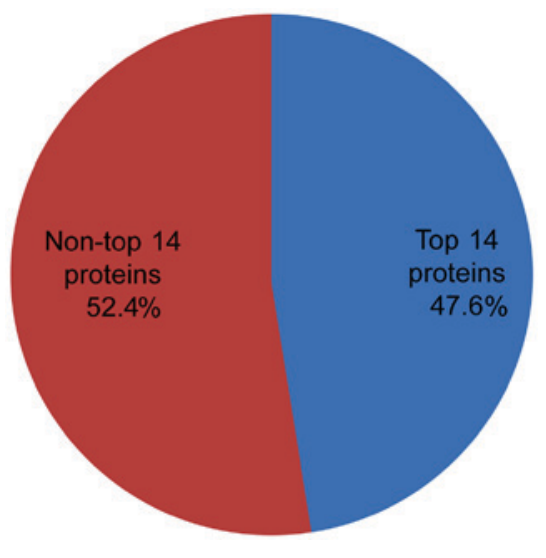

Figure 1. Proportion of the top 14 most abundant proteins.

identified a total of 124 proteins that were present in the patient sample and not in the normal human urine proteome (Fig. 2). The levels of these 124 proteins may be increased in the urine of patients with nephrotic syndrome compared with in normal human urine. These 124 proteins are subsequently referred to as 'disease-associated proteins'.

Comparison of the urine proteome of patients with nephrotic syndrome and the normal human kidney proteome and normal human plasma proteome in PeptideAtlas, and the normal human kidney proteome in the Human Protein Atlas. Comparison of the present results with the normal human kidney $(n=3,375)$ and plasma $(n=2,568)$ data from PeptideAtlas (19) revealed 34 proteins ( $\geq 2$ unique peptides) that were present in the nephrotic syndrome urine proteome and the normal human kidney proteome, but not in the normal human plasma proteome (Fig. 3). Mapping of these 34 proteins against the Human Protein Atlas (20) confirmed the expression of 29 proteins in the kidney. These 29 proteins present in the nephrotic syndrome urine proteome (Table IV) may originate from kidney tissue and are subsequently referred to as 'kidney-derived proteins'.

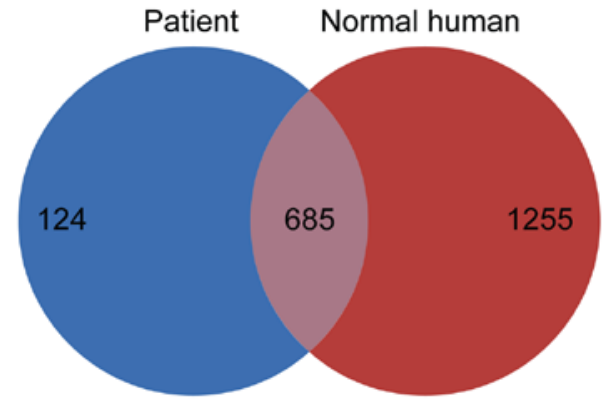

Figure 2. Comparison of the urine proteome of patients with nephrotic syndrome and the normal human urine proteome. A total of 124 proteins were present in the patient urine samples and not in the normal human urine proteome.

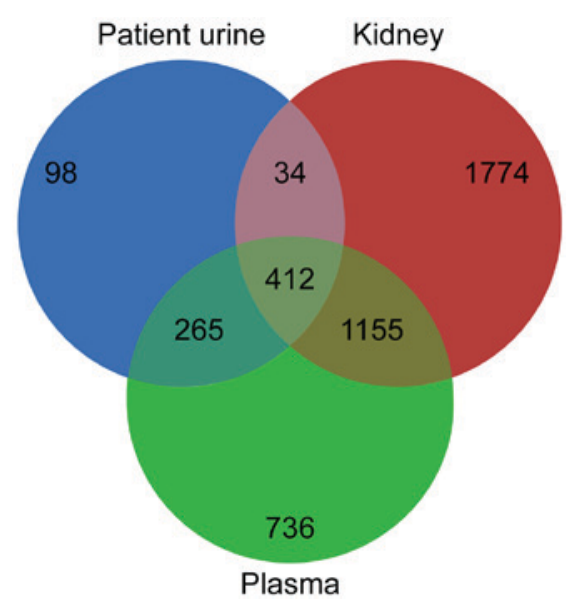

Figure 3. Comparison of the urine proteome of patients with nephrotic syndrome and the normal human kidney and normal human plasma proteomes in PeptideAtlas. A total of 34 proteins were present in the patient sample and normal human kidney proteome, and not in the normal plasma proteome.

Comparison of disease-associated proteins and kidney-derived proteins. A total of 13 low-abundance proteins 


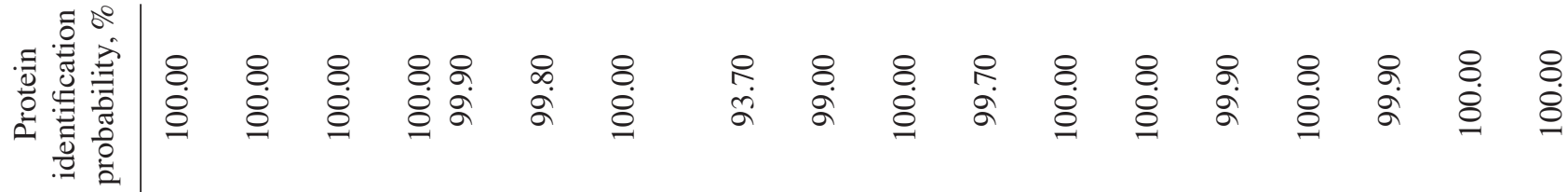

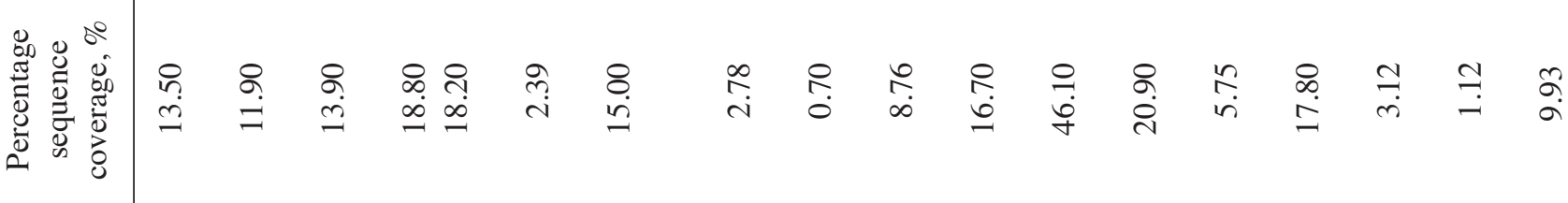

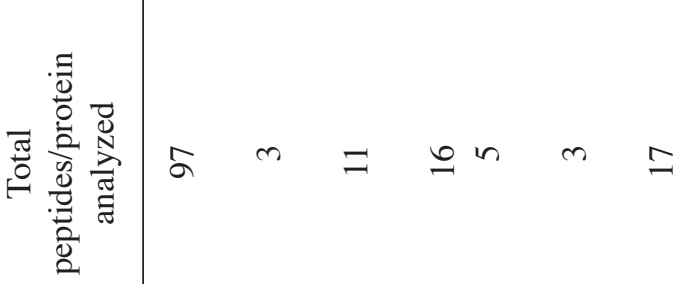

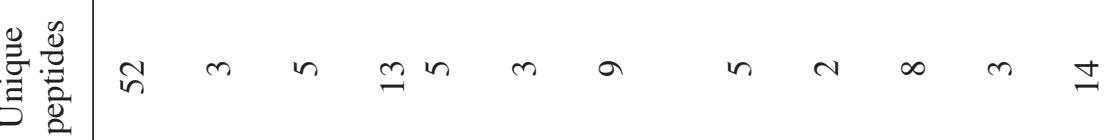

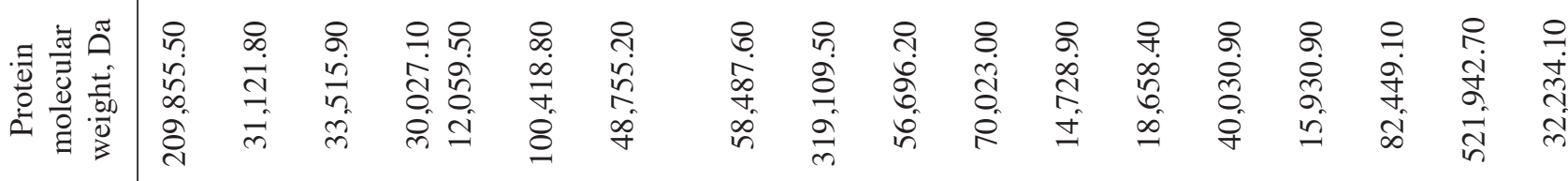

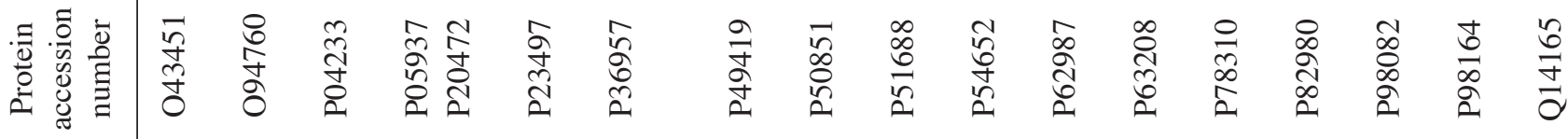

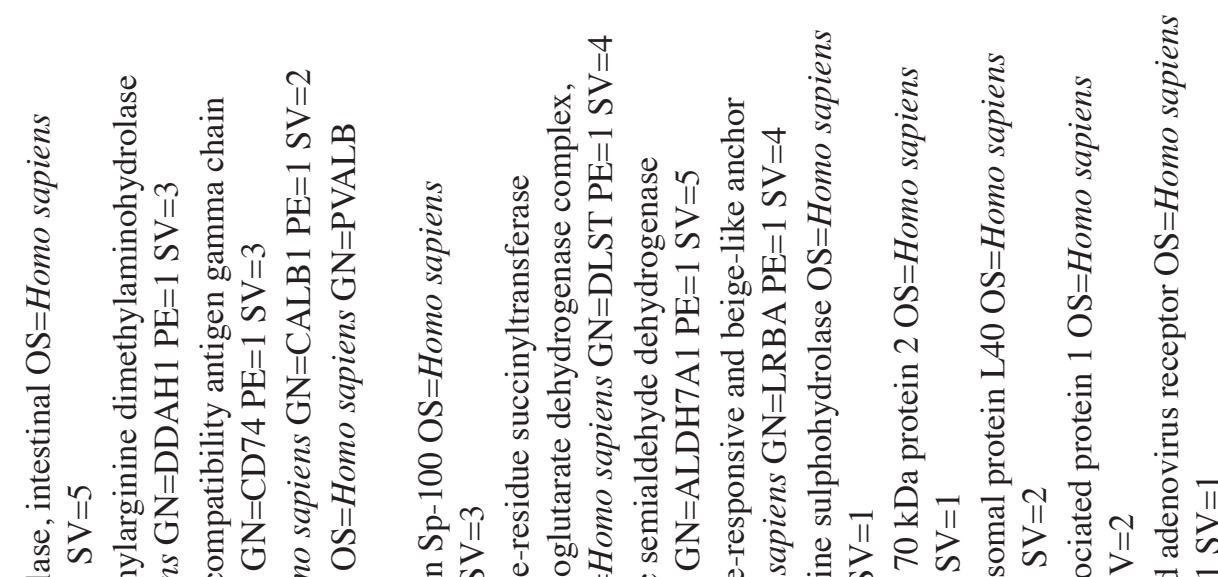

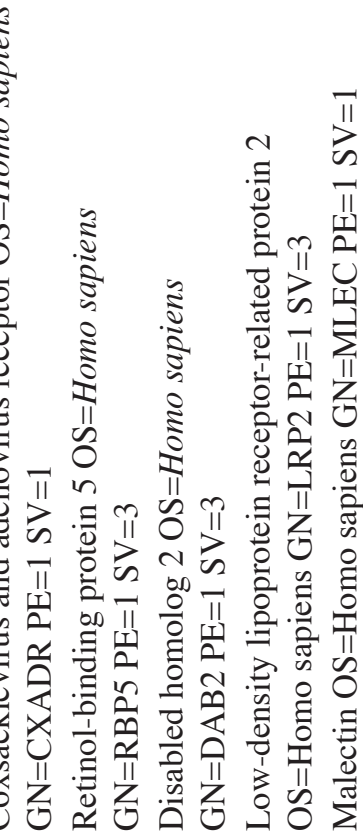




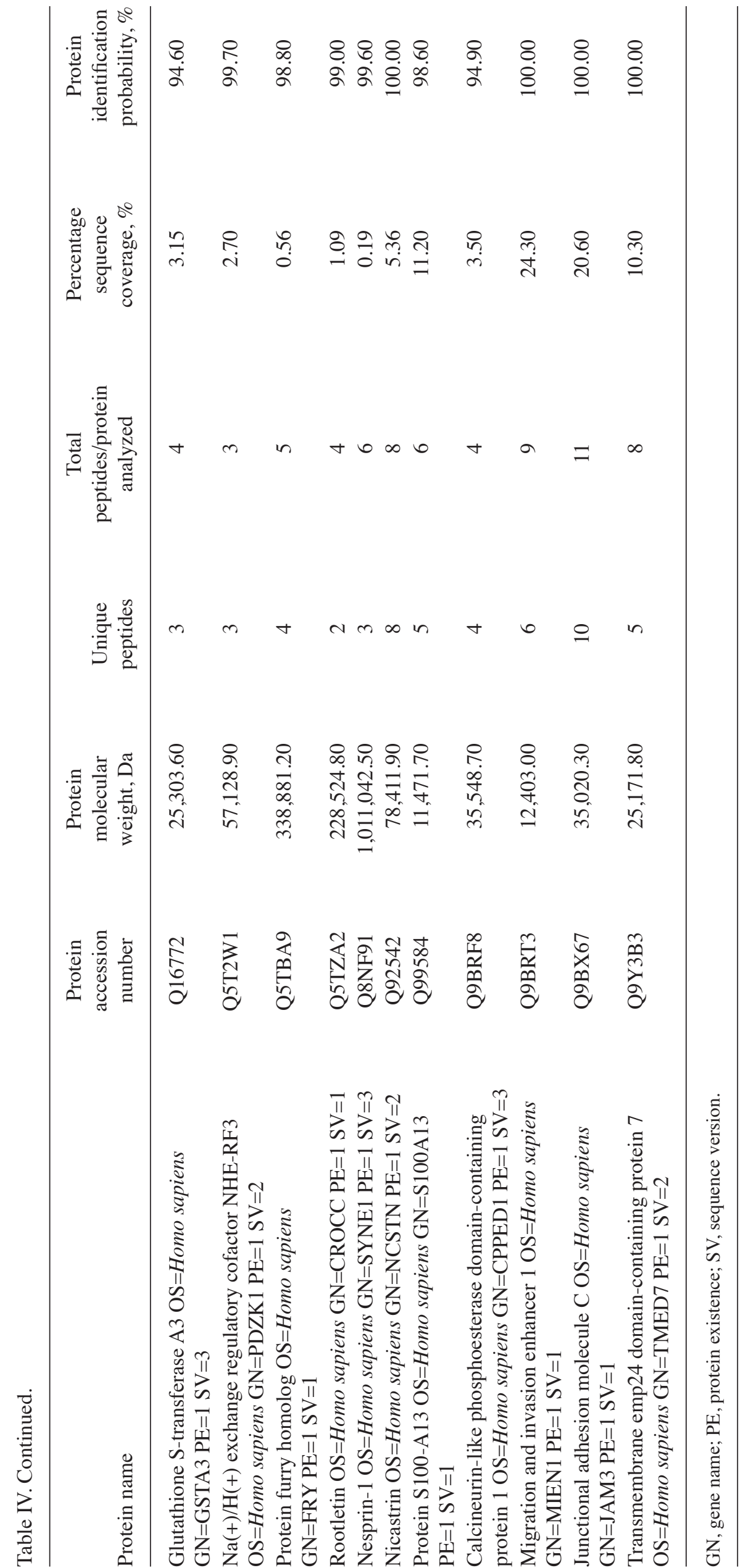


Table V. Kidney-derived disease-associated proteins.

\begin{tabular}{|c|c|c|c|c|}
\hline UniProt & Description & $\begin{array}{l}\text { Spectral } \\
\text { counting }\end{array}$ & $\begin{array}{c}\text { Molecular } \\
\text { weight, kDa }\end{array}$ & $\begin{array}{l}\text { Unique } \\
\text { peptides }\end{array}$ \\
\hline P62987 & Ubiquitin-60S ribosomal protein L40 & 169 & 15 & 14 \\
\hline P04233 & HLA class II histocompatibility antigen gamma chain & 11 & 34 & 5 \\
\hline P63208 & S-phase kinase-associated protein 1 & 8 & 19 & 7 \\
\hline P78310 & Coxsackievirus and adenovirus receptor & 6 & 40 & 5 \\
\hline Q99584 & Protein S100-A13 & 6 & 11 & 5 \\
\hline Q8NF91 & Nesprin-1 & 6 & 1,011 & 3 \\
\hline P20472 & Parvalbumin alpha & 5 & 12 & 5 \\
\hline Q5TBA9 & Protein furry homolog & 5 & 339 & 4 \\
\hline Q16772 & Glutathione S-transferase A3 & 4 & 25 & 3 \\
\hline Q5TZA2 & Rootletin & 4 & 229 & 2 \\
\hline P23497 & Nuclear autoantigen Sp-100 & 3 & 100 & 3 \\
\hline P50851 & Lipopolysaccharide-responsive and beige-like anchor protein & 2 & 319 & 2 \\
\hline P98082 & Disabled homolog 2 & 2 & 82 & 2 \\
\hline
\end{tabular}

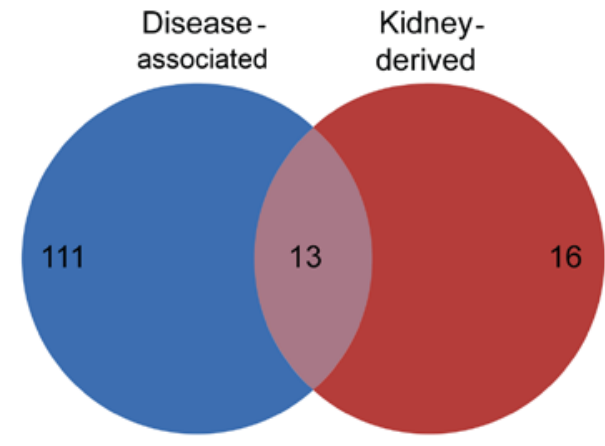

Figure 4. Comparison of disease-associated proteins and kidney-derived proteins. A total of 13 proteins were present in the disease-associated protein and kidney-derived protein groups.

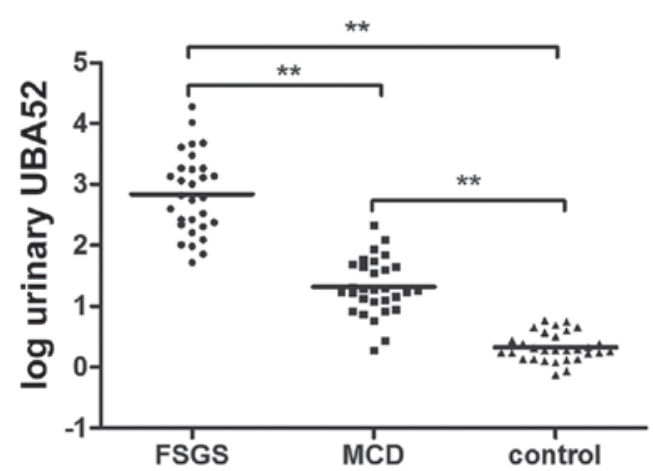

Figure 5. Comparison of urinary UBA52 levels in patients with FSGS and MCD, and healthy controls. The median for each group is represented by a horizontal line. ${ }^{* *} \mathrm{P}<0.001$. FSGS, focal segmental glomerulosclerosis; MCD, minimal change disease; UBA52, ubiquitin-60S ribosomal protein L40.

were present in the categories of disease-associated proteins and kidney-derived proteins. These 13 proteins represented kidney-derived proteins, which were increased in the urine collected from patients with nephrotic syndrome and not in healthy human urine. The presence of these proteins in the patient urine samples may be a result of injury to the kidney, and they are subsequently referred to as 'kidney-derived disease-associated proteins' (Fig. 4; Table V).

Validation of kidney-derived disease-associated proteins. Samples from 30 patients with FSGS, 30 patients with MCD and 30 healthy controls were analyzed using ELISA. The clinical and laboratory characteristics of the patients are summarized in Table II. The patients with FSGS were older compared with the patients with MCD $(\mathrm{P}=0.01)$. In addition, the patients with FSGS exhibited increased serum creatinine levels compared with the patients with $\mathrm{MCD}(\mathrm{P}=0.001)$. There were no significant differences in the sex ratios, 24-h urine protein levels, serum albumin levels or serum cholesterol levels between the two groups. The measured urinary UBA52 levels are presented in Fig. 5. Urinary UBA52 was barely detectable in the urine of healthy control subjects. The urinary UBA52 levels were increased in patients with FSGS and MCD compared with the healthy controls [Creatinine, $637 \mathrm{ng} / \mathrm{mg}(216-1,851)$ vs. $1.89 \mathrm{ng} / \mathrm{mg}$ (1.37-3.33), $\mathrm{P}<0.001$; and $18.58 \mathrm{ng} / \mathrm{mg}$ (11.11-46.25) vs. $1.89 \mathrm{ng} / \mathrm{mg}$ (1.37-3.33), $\mathrm{P}<0.001)]$, and were significantly increased in the patients with FSGS compared with in the patients with MCD.

\section{Discussion}

The present study identified a large number of proteins $(n=807)$ in the urine samples of patients with nephrotic syndrome. To the best of our knowledge, this result represents the largest urine proteomic profile of nephrotic syndrome to date. Urinary proteins were enriched using acetone precipitation. It has previously been reported that acetone precipitation exhibits the best performance among organic solvents according to enriched total protein, protein types and separation efficiency (23). The application of albumin/IgG antibody depletion decreased the abundance of albumins and other highly abundant proteins in the urine sample. The top 14 identified proteins still accounted for $<50 \%$ of the total amount of protein, suggesting that there remains the possibility of further improvement. In addition, the 
use of 2D-LC and high performance mass spectrometry in the present study facilitated the identification of low-abundance proteins.

The aim of the present study was to identify disease-specific kidney-derived proteins via a number of experimental stages. By comparing the urine proteome of patients with the normal human urine proteome, disease-associated proteins were identified. By eliminating protein overlap between normal human plasma and the urine proteome of patients, urinary protein derived from plasma were excluded. Among the remaining proteins in the urine proteome of the patients, the proteins that overlapped with the kidney proteome in PeptideAtlas were regarded as putative kidney-derived proteins; among these, the proteins that were detected in the kidney proteome of Protein Atlas were referred to as kidney-derived proteins. Comparison of kidney-derived proteins and disease-associated proteins revealed 13 kidney-derived disease-associated proteins in the urine proteome of patients with nephrotic syndrome.

UBA52 was the most abundant protein among the 13 low-abundance proteins. A component of the ubiquitin-proteasome system (UPS), UBA52 is a fusion protein composed of ubiquitin and the $60 \mathrm{~S}$ ribosomal protein L40, which labels proteins for degradation. To the best of our knowledge, UBA52 has not previously been reported to be present in the urine of patients with nephrotic syndrome, and has not been associated with nephrotic syndrome in the literature. A previous study reported that the proteolytic activity of UPS was increased in FSGS kidney tissue, although not in MCD, which may be associated with the different prognosis and therapeutic response of patients with FSGS and MCD (24). FSGS and MCD are prevalent forms of nephrotic syndrome. It is difficult to differentiate between FSGS and MCD clinically, even using renal biopsy. In the present study, validation experiments were performed to confirm the increased UBA52 levels in the urine of patients with nephrotic syndrome compared with healthy controls. It was additionally observed that UBA52 levels were increased in the urine of patients with FSGS compared with MCD, which is consistent with an increase in UPS activity in the kidney, suggesting that the 13 identified proteins (including UBA52) may be used to differentiate between pathological types of nephrotic disease, as they reflect pathological alterations in the kidney.

One of the primary limitations of analysis of the urine proteome in nephrotic syndrome is the difficulty in detecting low-medium abundance proteins, due to interference from filtered highly abundant plasma proteins. Further studies are required to ameliorate this limitation, which may facilitate the identification of biomarkers that reflect certain pathological types, injury sites and underlying pathological processes. In conclusion, the present study identified numerous potential novel urinary protein biomarkers for nephrotic syndrome. In addition, to the best of our knowledge, the present study obtained the largest urinary proteomic profile of patients with nephrotic syndrome to date.

\section{References}

1. Sancho-Martínez SM, Prieto-García L, Blanco-Gozalo V, Fontecha-Barriuso M,López-Novoa JM and López-Hernández FJ: Urinary proteomics in renal pathophysiology: Impact of proteinuria. Proteomics Clin Appl 9: 636-640, 2015
2. Somparn P, Hirankarn N, Leelahavanichkul A, Khovidhunkit W, Thongboonkerd V and Avihingsanon Y: Urinary proteomics revealed prostaglandin $\mathrm{H}(2) \mathrm{D}$-isomerase, not $\mathrm{Zn}$ - $\alpha 2$-glycoprotein, as a biomarker for active lupus nephritis. J Proteomics 75: 3240-3247, 2012

3. Zhang X, Jin M, Wu H, Nadasdy T, Nadasdy G, Harris N, Green-Church K, Nagaraja H, Birmingham DJ, Yu CY, et al: Biomarkers of lupus nephritis determined by serial urine proteomics. Kidney Int 74: 799-807, 2008.

4. Rossing K, Mischak H, Dakna M, Zürbig P, Novak J, Julian BA, Good DM, Coon JJ, Tarnow L and Rossing P; PREDICTIONS Network: Urinary proteomics in diabetes and CKD. J Am Soc Nephrol 19: 1283-1290, 2008.

5. Candiano G, Musante L, Bruschi M, Petretto A, Santucci L, Del Boccio P, Pavone B, Perfumo F, Urbani A, Scolari F and Ghiggeri GM: Repetitive fragmentation products of albumin and alpha1-antitrypsin in glomerular diseases associated with nephrotic syndrome. J Am Soc Nephrol 17: 3139-3148, 2006.

6. Varghese SA, Powell TB, Budisavljevic MN, Oates JC, Raymond JR, Almeida JS and Arthur JM: Urine biomarkers predict the cause of glomerular disease. J Am Soc Nephrol 18: 913-922, 2007.

7. Siwy J, Zoja C, Klein J, Benigni A, Mullen W, Mayer B, Mischak H, Jankowski J, Stevens R, Vlahou A, et al: Evaluation of the zucker diabetic fatty (ZDF) rat as a model for human disease based on urinary peptidomic profiles. PLoS One 7: e51334, 2012

8. Pieper R, Su Q, Gatlin CL, Huang ST, Anderson NL and Steiner S: Multi-component immunoaffinity subtraction chromatography: An innovative step towards a comprehensive survey of the human plasma proteome. Proteomics 3: 422-432, 2003.

9. Pernemalm M, Lewensohn R and Lehtiö J: Affinity prefractionation for MS-based plasma proteomics. Proteomics 9: 1420-1427, 2009.

10. Björhall K, Miliotis T and Davidsson P: Comparison of different depletion strategies for improved resolution in proteomic analysis of human serum samples. Proteomics 5: 307-317, 2005.

11. Desrosiers RR, Beaulieu E, Buchanan M and Béliveau R: Proteomic analysis of human plasma proteins by two-dimensional gel electrophoresis and by antibody arrays following depletion of high-abundance proteins. Cell Biochem Biophys 49: 182-195, 2007.

12. Echan LA, Tang HY, Ali-Khan N, Lee K and Speicher DW: Depletion of multiple high-abundance proteins improves protein profiling capacities of human serum and plasma. Proteomics 5: 3292-3303, 2005.

13. Roche S, Tiers L, Provansal M, Seveno M, Piva MT, Jouin P and Lehmann S: Depletion of one, six, twelve or twenty major blood proteins before proteomic analysis: The more the better? J Proteomics 72: 945-951, 2009.

14. Mebazaa A, Vanpoucke G, Thomas G, Verleysen K, Cohen-Solal A, Vanderheyden M, Bartunek J, Mueller C, Launay JM, Van Landuyt $\mathrm{N}$, et al: Unbiased plasma proteomics for novel diagnostic biomarkers in cardiovascular disease: Identification of quiescin Q6 as a candidate biomarker of acutely decompensated heart failure. Eur Heart J 33: 2317-2324, 2012.

15. Wang C, Wei LL, Shi LY, Pan ZF, Yu XM, Li TY, Liu CM, Ping ZP, Jiang TT, Chen ZL, et al: Screening and identification of five serum proteins as novel potential biomarkers for cured pulmonary tuberculosis. Sci Rep 5: 15615, 2015.

16. Kurono S, Kaneko Y, Matsuura N, Oishi H, Noguchi S, Kim SJ, Tamaki Y, Aikawa T, Kotsuma Y, Inaji H and Matsuura S: Identification of potential breast cancer markers in nipple discharge by protein profile analysis using two-dimensional nano-liquid chromatography/nanoelectrospray ionization-mass spectrometry. Proteomics Clin Appl 10: 605-613, 2016.

17. Cao TH, Quinn PA, Sandhu JK, Voors AA, Lang CC, Parry HM, Mohan M, Jones DJ and Ng LL: Identification of novel biomarkers in plasma for prediction of treatment response in patients with heart failure. Lancet 385 (Suppl 1): S26, 2015.

18. Jia L, Zhang L, Shao C, Song E, Sun W, Li M and Gao Y: An attempt to understand kidney's protein handling function by comparing plasma and urine proteomes. PLoS One 4: e5146, 2009.

19. Farrah T, Deutsch EW, Omenn GS, Sun Z, Watts JD, Yamamoto T, Shteynberg D, Harris MM and Moritz RL: State of the human proteome in 2013 as viewed through peptideatlas: Comparing the kidney, urine, and plasma proteomes for the biology- and disease-driven human proteome project. J Proteome Res 13: 60-75, 2014. 
20. Uhlen M, Oksvold P, Fagerberg L, Lundberg E, Jonasson K, Forsberg M, Zwahlen M, Kampf C, Wester K, Hober S, et al Towards a knowledge-based human protein atlas. Nat Biotechnol 28: 1248-1250, 2010.

21. Zhang L, Wen Q, Mao HP, Luo N, Rong R, Fan JJ and Yu XQ: Developing a reproducible method for the high-resolution separation of peritoneal dialysate proteins on 2-D gels. Protein Expr Purif 89: 196-202, 2013.

22. Wiśniewski JR, Zougman A, Nagaraj N and Mann M: Universal sample preparation method for proteome analysis. Nat Methods 6: 359-362, 2009
23. Thongboonkerd V, Chutipongtanate S and Kanlaya R: Systematic evaluation of sample preparation methods for gel-based human urinary proteomics: Quantity, quality, and variability. J Proteome Res 5: 183-191, 2006.

24. Beeken M, Lindenmeyer MT, Blattner SM, Radón V, Oh J, Meyer TN, Hildebrand D, Schlüter H, Reinicke AT, Knop JH, et al: Alterations in the ubiquitin proteasome system in persistent but not reversible proteinuric diseases. J Am Soc Nephrol 25: 2511-2525, 2014 